\title{
ACVBP Regimen
}

National Cancer Institute

\section{Source}

National Cancer Institute. ACVBP Regimen. NCI Thesaurus. Code C63446.

A regimen consisting of doxorubicin, cyclophosphamide, vindesine, bleomycin and prednisone used to treat aggressive forms of non-Hodgkin lymphoma. 